\title{
Psychological well-being, marital adjustment and quality of life after hysterectomy: a comparative study
}

\author{
Kusum Lata Mathur ${ }^{1 *}$, Manu Sharma², Mohua Mazumdar ${ }^{2}$, \\ Shikha Talati ${ }^{2}$, Siddharth Srivastav ${ }^{1}$
}

\begin{abstract}
${ }^{1}$ Department of Obstetrics and Gynecology, ${ }^{2}$ Department of Psychiatry, Geetanjali Medical College and Hospital,
\end{abstract} Udaipur, Rajasthan, India

Received: 19 September 2018

Accepted: 22 October 2018

\section{*Correspondence:}

Dr. Manu Sharma,

E-mail: drmanusharma5@gmail.com

Copyright: (c) the author(s), publisher and licensee Medip Academy. This is an open-access article distributed under the terms of the Creative Commons Attribution Non-Commercial License, which permits unrestricted non-commercial use, distribution, and reproduction in any medium, provided the original work is properly cited.

\begin{abstract}
Background: Hysterectomy is the most common major gynecological surgery often performed for benign lesions. Many studies have reported adverse psychosocial outcomes post-hysterectomy. There is a paucity of studies from India addressing psychiatric morbidity after hysterectomy. To evaluate psychological wellbeing, marital adjustment and quality of life in patients undergoing hysterectomy for non-malignant conditions, in comparison with patients undergoing surgery other than hysterectomy.

Methods: A cross-sectional study was conducted on 100 consecutive out-patients who underwent hysterectomy for non-malignant indications at least 6 months ago. The comparison group comprised of 50 consecutive out-patients who underwent gynecological surgery other than hysterectomy at least 6 months ago formed the comparison group. The study participants were evaluated on Hospital Anxiety and Depression Scale (HADS), Psychological General Wellbeing Index (PGWBI), Marital Adjustment Test (MAT) and Women's Quality of Life Questionnaire (WOMQOL).

Results: The indications for hysterectomy were: uterine leiomyoma (69\%), uterovaginal prolapse (18\%), dysfunctional uterine bleeding (12\%), and endometriosis (1\%). Abdominal hysterectomy was performed in 92 patients while 8 patients underwent vaginal hysterectomy. There were no significant differences in the study groups on scores of HADS, PGWBI, MAT and WOMQOL ( $p>0.05$ ). Both the study groups had good marital adjustment and majority reported no depression and anxiety.

Conclusions: There is no major psychiatric morbidity, decline in marital adjustment and quality of life after hysterectomy for benign conditions among Indian women. Future research on the ethno-cultural implications and effect of hysterectomy on mental health will be a significant addition to the available evidence in India.
\end{abstract}

Keywords: Hysterectomy, Marital adjustment, Psychological well-being, Quality of life

\section{INTRODUCTION}

Hysterectomy is the most common major gynecological operation, often performed for benign conditions and as such is performed in order to improve women's quality of life (QOL). Hysterectomy is theorized to cause depression because of the perceived loss of feminine selfimage, strength, and self-esteem, as well as feelings of deformation, mutilation, and the mourning of the loss of child-bearing capacity. $^{1-2}$ The uterus symbolizes femininity, childbearing, sexuality, strength, vitality, youth, attractiveness, competency, regulation of body processes, and control of the rhythm of life. ${ }^{3}$ There is evidence suggesting that hysterectomy without oophorectomy does not cause depression. ${ }^{4}$ However, presurgical depression and anxiety, psychological well-being or postmenopausal changes, might put women at greater risk for negative psychosexual outcomes. ${ }^{4}$ 
Sexual functioning following hysterectomy is a major concern of patients. ${ }^{5}$ Anticipatory guidance regarding decreased libido, physical changes, loss and grief reactions, and the possible complications of surgery can affect sexual functioning, marital adjustment, and consequently, QOL after hysterectomy.

Many women also fear that their partners will see them differently following a hysterectomy. ${ }^{6,7}$ Positive outcomes of hysterectomy include decreases in chronic pelvic pain and pain during intercourse, as well as the elimination of menstrual pain and dysfunctional uterine bleeding. ${ }^{8-9}$

However, hysterectomy may sometimes result in new symptoms related to pain, sexual dysfunction, and psychological distress, as well as in long-term adverse effects related to ovarian failure. ${ }^{3}$ Benign gynecological disorders have a clear negative impact on women's health and functioning, and pelvic pain is a major problem for these patients, which negatively correlates with QOL. ${ }^{10}$

Some researchers have reported adverse sequelae of hysterectomy such as depression, psychosis, anxiety and psychosomatic disturbances. ${ }^{11-13}$ On the contrary, few prospective studies concluded that hysterectomy does not lead to psychiatric disorders. ${ }^{14-15}$ There is a paucity of Indian research in this area.

Two Indian studies reported significantly higher psychiatric morbidity following hysterectomy while two other studies did not. Studies published so far are limited by variations in sample size, timing of assessment and study instruments. ${ }^{16-19}$ The authors undertook the present investigation to address the research lacunae with the aim to evaluate psychological wellbeing, marital adjustment and QOL in patients undergoing hysterectomy for nonmalignant conditions.

\section{METHODS}

This cross-sectional, comparative and observational study was conducted in the Departments of Obstetrics and Gynecology, and Psychiatry at Geetanjali Medical College and Hospital, Udaipur, Rajasthan, India between December 2017 and June 2018. The study was initiated after approval from the Institution Ethics Committee. A written informed consent was obtained from all the study participants. The study group comprised of 100 consecutive adult out-patients who underwent abdominal or vaginal hysterectomy at least 6 months ago.

The comparison group consisted of 50 out-patients who have undergone gynecological surgery other than hysterectomy 6 months ago. Patients with malignancy in the genital organs; previous or present cervical dysplasia; rapidly growing fibroids where malignancy could not be ruled out; preoperative treatment with $\mathrm{GnRH}$ analogues; postmenopausal women without hormone therapy; history of a psychiatric disorder (other than nicotine use disorders); history and/or evidence of other uncontrolled/untreated medical illness (such as hypertension, diabetes mellitus, rheumatological disorders, thyroid dysfunction, dermatological conditions, etc); requiring intensive care management were excluded. The socio-demographic and clinical data such as age, marital status, domicile, education level, nature of gynecological disorder, indication for hysterectomy and other surgery was recorded on a specific proforma designed for the study. The following tools were used:

The Hospital Anxiety and Depression Scale (HADS) was originally designed to assess psychological distress of patients in medical and surgical settings. ${ }^{20}$ Several studies have documented and confirmed its validity in varying clinical settings, and the translations are found to be cross-culturally stable as the original tool. ${ }^{21-23}$

The HADS contains 14 items and consists of two subscales: anxiety and depression.

Each item is rated on a four-point scale of 0-3, giving maximum scores of 21 for anxiety and depression respectively. Scores of 11 or more on either subscales are considered to be a significant 'case' of psychological morbidity (clinical caseness), while scores of 8-10 represent 'mood disorder'. A score of 7 or below is considered as normal. The same cut-offs for HADS in Indian population were found to be nearly 85 per cent sensitive and 88 per cent specific. ${ }^{24}$

Marital Adjustment Test 25 (MAT) is a 15-item scale that measures marital satisfaction. Researchers have been trying to clearly define marital adjustment and understand which factors contribute to a well-adjusted marriage, even though no consensus has been reached. Locke and Wallace (1959) defined it as "accommodation of a husband and wife to each other at given time."

MAT was initially used to differentiate well-adjusted couples from distressed (unsatisfied) couples. ${ }^{25}$ The 15 items are answered on a variety of response scales. The total scores are the sum of each item and range from 2 to 158. Higher scores indicate greater satisfaction. ${ }^{25}$

The Women's Quality of Life questionnaire (WOMQOL): Quality of life is a multi-dimensional construct and defined subjectively. The WOMQOL was developed as part of a community-based study of women's health, including mental health through the menstrual cycle with no known pathology. ${ }^{26}$

A generic conceptualization of QOL was used in the construction of the measure that weighted health and nonhealth factors to ensure the representation of the life experiences of a broad range of women in the community-based Women Wellness study. ${ }^{26}$ The participants were asked to answer "yes", "no" or "not applicable" to the 40 questions in the WOMQOL based on how they have felt in the last week of their life. 
The Psychological General Well-being Index (PGWI) contains 22 questions, covering the six subscales anxiety, depressed mood, positive well-being, general health, vitality and self-control. ${ }^{27}$

The validity and reliability of this instrument are well documented, and it has previously been used to compare patient groups and to determine the effect of an intervention on the patient's sense of subjective wellbeing. ${ }^{27,28}$

\section{Data analysis}

Statistical analyses were done using the Statistical Package for Social Sciences (SPSS) version 16.0 for
Windows. Discrete co-variates were expressed as frequencies and compared between groups with chisquare test. Continuous co-variates were expressed as mean with standard deviation (SD) and compared between groups using the unpaired student's t-test. All statistical analysis was done at $95 \%$ confidence interval and $\mathrm{p}<0.05$ was considered significant.

\section{RESULTS}

The hysterectomy group and non-hysterectomy comparison group were not statistically different on socio-demographic characteristics such as age, marital status, domicile and education attainment (Table 1).

Table 1: Socio-demographic and clinical profile of the hysterectomy and non-hysterectomy study groups.

\begin{tabular}{|lll|}
\hline Variable & Hysterectomy group $(\mathbf{N}=100)$ & Non-hysterectomy group (N=50) \\
\hline Mean \pm SD (years) & $44.68 \pm 49.0$ & $43.18 \pm 6.58$ \\
\hline$<40$ years & $11(11 \%)$ & $16(32 \%)$ \\
\hline $40-49$ years & $78(78 \%)$ & $29(58 \%)$ \\
\hline$\geq 50$ years & $11(11 \%)$ & $5(10 \%)$ \\
\hline Marital status & & $48(96 \%)$ \\
\hline Married & $99(99 \%)$ & $2(4 \%)$ \\
\hline Not currently married & $1(1 \%)$ & $36(72 \%)$ \\
\hline Domicile & $72(72 \%)$ & $14(28 \%)$ \\
\hline Urban & $28(28 \%)$ & $08(16 \%)$ \\
\hline Rural & $24(24 \%)$ & $30(60 \%)$ \\
\hline Education & $58(58 \%)$ & $12(24 \%)$ \\
\hline Primary school & $18(18 \%)$ & \\
\hline High school & & \\
\hline College & & \\
\hline
\end{tabular}

Table 2: Mean scores of the hysterectomy and non-hysterectomy group on study measures.

\begin{tabular}{|c|c|c|c|c|c|c|}
\hline Variable & Group & $\mathbf{N}$ & Mean & Std. Deviation & $' t '$ & P value \\
\hline \multirow{2}{*}{ Age (years) } & Non-hysterectomy & 50 & 43.18 & 6.580 & \multirow{2}{*}{1.570} & \multirow{2}{*}{0.119} \\
\hline & Hysterectomy & 100 & 44.68 & 4.905 & & \\
\hline \multirow{2}{*}{ HADS $^{1}$} & Non-hysterectomy & 50 & 4.58 & 3.065 & \multirow{2}{*}{1.074} & \multirow{2}{*}{0.285} \\
\hline & Hysterectomy & 100 & 5.35 & 4.580 & & \\
\hline \multirow{2}{*}{ WOMQOL $^{2}$} & Non-hysterectomy & 50 & 34.70 & 5.335 & \multirow{2}{*}{0.274} & \multirow{2}{*}{0.784} \\
\hline & Hysterectomy & 100 & 34.44 & 5.538 & & \\
\hline \multirow{2}{*}{$\mathrm{PGWBI}^{3}$} & Non-hysterectomy & 50 & 85.72 & 10.264 & \multirow{2}{*}{0.412} & \multirow{2}{*}{0.681} \\
\hline & Hysterectomy & 100 & 84.79 & 14.224 & & \\
\hline \multirow{2}{*}{$\mathrm{MAT}^{4}$} & Non-hysterectomy & 50 & 102 & 10.45 & \multirow{2}{*}{0.321} & \multirow{2}{*}{0.612} \\
\hline & Hysterectomy & 100 & 110 & 8.91 & & \\
\hline
\end{tabular}

${ }^{1}$ Hospital anxiety and depression scale; ${ }^{2}$ Women's quality of life questionnaire; ${ }^{3}$ Psychological general well-being index; ${ }^{4}$ Marital adjustment scale.

The indications for hysterectomy were: uterine leiomyoma (69\%), uterovaginal prolapse (18\%), dysfunctional uterine bleeding (12\%), and endometriosis (1\%). Abdominal hysterectomy was performed in 92 patients while 8 patients underwent vaginal hysterectomy. The mean scores of the study groups on measures of depression and anxiety, psychological wellbeing, QOL and marital adjustment are shown in Table 2. Majority of patients in both study groups had no depressive and anxiety symptoms. Three percent of 
patients in both study groups scored $>21$ on HADS. There were no significant differences in the study groups on these measures. Both the study groups and good marital adjustment and majority reported no depression and anxiety (Tables 3 and 4).

Table 3: Number of patients with anxiety and depression in the hysterectomy and non-hysterectomy.

\begin{tabular}{|c|c|c|c|c|c|c|}
\hline \multirow{2}{*}{ Groups } & & \multicolumn{4}{|c|}{ HADS $^{1}$ score } & \multirow{2}{*}{ Total } \\
\hline & & 0 to 7 & 8 to 10 & 11 to 21 & $>21$ & \\
\hline \multirow{2}{*}{ Non-hysterectomy } & $\mathrm{F}$ & 42 & 5 & 3 & 0 & 50 \\
\hline & $\%$ & $84.0 \%$ & $10.0 \%$ & $6.0 \%$ & $0.0 \%$ & $100.0 \%$ \\
\hline \multirow{2}{*}{ Hysterectomy } & $\mathrm{F}$ & 82 & 9 & 6 & 3 & 100 \\
\hline & $\%$ & $82.0 \%$ & $9.0 \%$ & $6.0 \%$ & $3.0 \%$ & $100.0 \%$ \\
\hline \multirow{2}{*}{ Total } & $\mathrm{F}$ & 124 & 14 & 9 & 3 & 150 \\
\hline & $\%$ & $82.7 \%$ & $9.3 \%$ & $6.0 \%$ & $2.0 \%$ & $100.0 \%$ \\
\hline Chi Square ( $\mathrm{p}$ value) & & 1.552( & & & & \\
\hline
\end{tabular}

${ }^{1}$ Hospital anxiety and depression Scale

Table 4: Marital adjustment in the hysterectomy and non-hysterectomy groups.

\begin{tabular}{|c|c|c|c|c|c|c|}
\hline \multirow{2}{*}{ Groups } & & & \multicolumn{3}{|c|}{$\mathrm{MAT}^{1}$} & \multirow{2}{*}{ Total } \\
\hline & & & NA & Distress & ND & \\
\hline & \multirow{2}{*}{ Non-hysterectomy } & $\mathrm{F}$ & 0 & 12 & 38 & 50 \\
\hline & & $\%$ & $0.0 \%$ & $24.0 \%$ & $76.0 \%$ & $100.0 \%$ \\
\hline & \multirow{2}{*}{ Hysterectomy } & $\mathrm{F}$ & 1 & 29 & 70 & 100 \\
\hline & & $\%$ & $1.0 \%$ & $29.0 \%$ & $70.0 \%$ & $100.0 \%$ \\
\hline \multirow{2}{*}{ Total } & & $\mathrm{F}$ & 1 & 41 & 108 & 150 \\
\hline & & $\%$ & $0.7 \%$ & $27.3 \%$ & $72.0 \%$ & $100.0 \%$ \\
\hline Chi Square (p value) & \multicolumn{6}{|c|}{$0.972(0.615)$} \\
\hline
\end{tabular}

${ }^{1}$ Marital adjustment test

\section{DISCUSSION}

The authors aimed to evaluate prevalence of anxiety and depressive symptoms, psychological well-being, marital adjustment and QOL in women post-hysterectomy in comparison to women undergoing gynecological surgery other than hysterectomy at a tertiary care centre. The most common indication for a hysterectomy was uterine leiomyoma followed by uterovaginal prolapse. This observation is consistent with findings of previous investigations. ${ }^{28,29}$

Earlier studies have reported higher prevalence of psychiatric morbidity post-hysterectomy. ${ }^{16,17,30-34}$ The findings of the present study indicate that a minority of patients after hysterectomy have depression and anxiety (Table 3). Earlier investigations indicate a link between hysterectomy and depressive illness. ${ }^{2}$ Vyas et al 20 and Subramaniam et al reported prevalence of depression following hysterectomy to be around 20\%. ${ }^{21}$ Psychiatric complaints were found in $30 \%$ of women posthysterectomy by Ackner. ${ }^{33}$ The findings of the present study are in agreement with previous researchers who found no significant increase in depressive disorders after hysterectomy. ${ }^{18}$ Present study found most women as having good QOL and marital adjustment which is consistent with the observations of earlier studies. ${ }^{11,35}$ Genital prolapse is commoner in the elderly. It is possible that women with this diagnosis could have viewed their clinical condition as part of aging process, therefore, coped well. Likewise, the resolution of disturbing menorrhagia in those with dysfunctional uterine bleeding might explain the lack of any significant psycho-social morbidity. Hysterectomy is effective in reducing dyspareunia and pelvic pain which may translate into better sexual functioning, and consequently better marital adjustment and QOL. ${ }^{35,36}$

Anxiety and depression have been reported to be associated with hysterectomy. ${ }^{37} \mathrm{~A}$ review by Flory and colleagues reported that hysterectomy had negative shortand long-term psychological consequences for some women. Long after the procedure several psychological symptoms were still more common among women who had undergone hysterectomy. ${ }^{38}$ In a study, no differences were noted at 6 months in the psychological well-being of women who underwent abdominal compared with women who underwent laparoscopic hysterectomy. ${ }^{39}$ Such differences in outcome may result from differences in study design, including retrospective vs. prospective design, length of follow-up, and population selection. Recent prospective studies have determined that no negative effects resulted from hysterectomy overall, and some authors have even found positive effects of hysterectomy on the psychosocial and sexual well-being of women. ${ }^{35,38}$ Most of these studies were conducted in 
industrialized countries. It is possible that cultural factors may contribute to the reaction to hysterectomy of women from different ethnic backgrounds, thereby influencing the findings across study populations. Fertility in women is valued highly in traditional Indian society and masculine roles are more dominant. The limitations of the present study are small sample size, cross-sectional study design and potential for self-report bias, therefore, the findings cannot be generalized. The use of standardized instruments and a comparison group are relative merits of the study. It has been demonstrated that the time frame for recovery from surgical damage to the pelvis can be as long as 6 months. By then, most women have resumed their pre-operative levels of sexual activity. ${ }^{5,34}$ Therefore, we studied assessed psycho-sexual and QOL at a minimum of 6 months post-operatively. The study adds to the empirical evidence which does not support any broad adverse effects of hysterectomy on women's psychosocial functioning.

There have been claims that hysterectomy results in some form of psychosexual or psychosocial impairment in a minority of patients warrants further multi-centric investigation in diverse ethno-cultural populations. , $^{5,40}$ Overall, the present investigation affirms current evidence which does not indicate that the removal of uterus causes or relieves psychopathology. ${ }^{38}$

\section{CONCLUSION}

This study suggests that there is no major psychiatric morbidity, decline in marital adjustment and QOL after hysterectomy for benign conditions among Indian women. Future multi-centric research on the peculiar socio-cultural implications, use of larger sample size and effect of hysterectomy will be a significant addition to the available evidence in India.

\section{Funding: No funding sources}

Conflict of interest: None declared

Ethical approval: The study was approved by the Institutional Ethics Committee

\section{REFERENCES}

1. Nathorst-Boos J, Fuchs T, von Schoultz B. Consumer's attitude to hysterectomy. The experience of 678 women. Acta Obstet Gynecol Scand 1992;71(3):230-4.

2. Polivy J. Psychological reactions to hysterectomy: a critical review. Am J Obstet Gynecol 1974;118(3):417-26.

3. Bachmann GA. Psychosexual aspects of hysterectomy. Womens Health Issues 1990;1(1):419.

4. Rhodes JC, Kjerulff KH, Langenberg PW, Guzinski GM. Hysterectomy and sexual functioning. JAMA 1999;282(20):1934-41.

5. Roovers JP, van der Bom JG, van der Vaart $\mathrm{CH}$, Heintz AP. Hysterectomy and sexual wellbeing: prospective observational study of vaginal hysterectomy, subtotal abdominal hysterectomy, and total abdominal hysterectomy. BMJ 2003;327(7418):774-8.

6. Williamson ML. Sexual adjustment after hysterectomy. J Obstet Gynecol Neonatal Nurs. 1992;21(1):42-7.

7. Vomvolaki E, Kalmantis K, Kioses E, Antsaklis A. The effect of hysterectomy on sexuality and psychological changes. The European Journal of Contraception and Reproductive Health Care. 2006;11(1):23-7.

8. Farquhar CM, Sadler L, Harvey S, McDougall J, Yazdi G, Meuli KA. Prospective study of the shortterm outcomes of hysterectomy with and without oophorectomy. Aust NZJ Obstet Gynaecol 2002;42(2):197-204.

9. Carlson KJ, Miller BA, Fowler FJ. The Maine Women's Health Study: II. Outcomes of nonsurgical management of leiomyomas Abnormal bleeding, and chronic pelvic pain. Obstet Gynecol. 1994;83(4):566-72.

10. Rannestad T, Eikeland OJ, Helland H, Qvarnström U. Quality of life, pain, and psychological well-being in women suffering from gynecological disorders. J Women's Health Gender Med. 2000;9(8):897-903.

11. Richards DH. A post-hysterectomy syndrome. The Lancet. 1974;304(7887):983-5.

12. Drellich MC, Bieber I. The psychological importance of the uterus and its functions. J Nerv Ment Dis. 1958;126(4):322-36.

13. Zervos SK, Papaloucas AL. Psychosomatic disturbances following hysterectomy performed at a premenopausal age. Int Surg. 1972;57(10):802-4.

14. Lambden MP, Bellamy G, Ogburn-Russell L, Preece CK, Moore S, Pepin T, et al. Women's sense of wellbeing before and after hysterectomy. J Obstet Gynecol Neonatal Nurs 1997;26(5):540-8.

15. Ryan MM. Hysterectomy: social and psychosexual aspects. Baillieres Clin Obstet Gynaecol. 1997;11(1):23-36.

16. Vyas JN, Rathore RS, Sharma P, Singhal AK. A study of psychiatric aspects of hysterectomy. Indian J Psychia. 1989;31(1):83-9.

17. Subramaniam D, Subramaniam SK, Charles SX, Verghese A. Psychiatric aspects of hysterectomy. Indian J Psychia. 1982;24(1):75.

18. Bhatia MS, Kaur N, Goyal U. Psychiatric reactions in hysterectomy. Indian J Psychia. 1990;32(1):52-6.

19. Col SC, Col TB. Psychiatric effects of hysterectomy. Medical Journal Armed Forces India. 1995 Jan $1 ; 51(1): 27-30$.

20. Zigmond AS, Snaith RP. The hospital anxiety and depression scale. Acta Psychiatr Scand 1983;67(6): 361-70.

21. Snaith RP. The hospital anxiety and depression scale. Health Qual Life Outcomes 2003;1(1):29.

22. Smith AB, Selby PJ, Velikova G, Stark D, Wright EP, Gould A, et al. Factor analysis of the hospital 
anxiety and depression scale from a large cancer population. Psychol Psychother 2002;75(2):165-76.

23. Montazeri A, Vahdaninia M, Ebrahimi M, Jarvandi S. The hospital anxiety and depression scale (HADS): translation and validation study of the Iranian version. Health Qual Life Outcomes 2003;1: 14.

24. Chaturvedi SK, Chandra PS, Channabasavanna SM, Beena MB, Pandian RD, Chandra PS. Detection of anxiety and depression in cancer patients. NIMHANS J. 1994;12:141-4.

25. Locke HJ, Wallace KM. Short marital-adjustment and prediction tests: Their reliability and validity. Marriage and Family Living. 1959;21(3):251-5.

26. Gehlert S, Chang CH, Bock RD, Hartlage SA. The WOMQOL instrument measured quality of life in women of reproductive age with no known pathology. J clinic epidemiol. 2006;59(5):525-33.

27. Dupuy H. The Psychological General Well-Being (PGWB) Index. In: Wenger NK, Mattson ME, Furber CD, Elinson J, eds. Assessment of quality of life in clinical trials of cardiovascular therapies. New York: LeJacq Publishing Inc, 1984:170-83.

28. Kluivers KB, Johnson NP, Chien P, Vierhout ME, Bongers M, Mol BW. Comparison of laparoscopic and abdominal hysterectomy in terms of quality of life: a systematic review. Europe J Obstet Gynecol Reproduct Biol. 2008;136(1):3-8.

29. Leung PL, Tsang SW, Yuen PM. An audit on hysterectomy for benign diseases in public hospitals in Hong Kong. Hong Kong Med J. 2007;13(3):18793.

30. El-Toukhy TA, Hefni M, Davies A, Mahadevan S. The effect of different types of hysterectomy on urinary and sexual functions: A prospective study. J Obstet Gynaecol. 2004;24(4):420-5.

31. Helmy YA, Hassanin IMA, Elraheem TA, Bedaiwy AA, Peterson RS, Bedaiwy, MA. Psychiatric morbidity following hysterectomy in Egypt. Int $\mathbf{J}$ Gynecol Obstet.2008;102(1):60-4.

32. Okunlola MA, Umuerri C, Omigbodun OO, Morhason-Bello IO, Okonkwo SN, Ojengbede OA. Pattern of mental ill health morbidities following hysterectomy for benign gynaecological disorders among Nigerian women. Int J Mental Health Syst. 2009;3(1):18.

33. Ackner B. Emotional aspects of hysterectomy. A follow-up study of fifty patients under the age of 40 . In: European Conference on Psychosomatic Research 1960 (Vol. 1, pp. 248-252). Karger Publishers.

34. Gath D, Cooper P, Day A. Hysterectomy and psychiatric disorder, I: levels of psychiatric disorder before and after hysterectomy. Br J Psychiatry 1982;140(4):335-42.

35. Thakar R, Ayers S, Georgakapolou A, Clarkson P, Stanton S, Manyonda I. Hysterectomy improves quality of life and decreases psychiatric symptoms: a prospective and randomised comparison of total versus subtotal hysterectomy. BJOG 2004;111(10):1115-20.

36. Sung MH, Lim YM. Factors affecting sexual satisfaction in Korean women who have undergone a hysterectomy. Austra J Advance Nurs, The. 2009;27(2):46.

37. Jawor M, Dimter A, Marek K, Dudek D, Wojtys A, Szproch A. Anxiety-depressive disorder in women after hysterectomy. Own study. [In Polish]. Psychiatr Pol 2001;35(5):771-80.

38. Flory N, Bissonnette F, Binik YM. Psychosocial effects of hysterectomy: literature review. J Psychosom Res. 2005;59(3):117-29.

39. Persson P, Wijma K, Hammar M, Kjolhede P. Psychological wellbeing after laparoscopic and abdominal hysterectomy-a randomised controlled multicentre study. BJOG 2006;113(9):1023-30.

40. Weber AM, Walters MD, Schover LR, Church JM, Piedmonte MR. Functional outcomes and satisfaction after abdominal hysterectomy. Prim Care Update Obstet Gynecols. 1998;5(4):203.

Cite this article as: Mathur KL, Sharma M, Mazumdar M, Talati S, Srivastav S. Psychological well-being, marital adjustment and quality of life after hysterectomy: a comparative study. Int J Reprod Contracept Obstet Gynecol 2018;7:4960-5. 